\title{
The Effect of Tourism Development on Economic Growth in Taiwan: Export Growth as Mediator
}

\author{
TZU-KUANG HSU ${ }^{1}$, I-HSUN TSAI ${ }^{2 *}$ \\ ${ }^{1}$ Department of Business Administration \\ Chung Hua University \\ No.707, Sec.2 WuFu Rd., Hsinchu, \\ Taiwan, R.O.C. \\ hsutk@chu.edu.tw \\ ${ }^{2} \mathrm{Ph}$. D Program of Technology Management \\ Chung Hua University \\ No.707, Sec.2 WuFu Rd., Hsinchu, \\ Taiwan, R.O.C. \\ d10503011@chu.edu.tw
}

Received: May 22, 2020, Revised: June 25, 2020. Accepted: July 23, 2020. Published: August 7, 2020.

\begin{abstract}
In this paper, we employed an innovative method, called a quantile mediation analysis, which combines a quantile regression and mediation analysis to examine the impact of tourism development on economic growth whether through export growth or not from 1990 to 2018 in Taiwan. The result of the traditional ordinary least square approach shows that Taiwan's tourism development affects economic growth through the full mediation effect of export growth for the period of 19902018 and there is no direct relation from tourism development to economic growth. Moreover, the results of this innovative analysis indicate that Taiwan's tourism development also affects economic growth through the full mediation effect of export growth at below 0.6 distributions of economic growth, but at above 0.6 distributions of economic growth, there exist direct and partially indirect effect from tourism development to economic growth. From the results, we suggest that Taiwan's government should focus on the export growth if she wants to promote Taiwan's economic growth when the economy is in a recession, not focus on tourism development.
\end{abstract}

Keywords- a quantile mediation analysis; tourism development; export growth; economic growth

\section{Introduction}

Whether tourism development promotes economic growth is still the controversial issue among scholars and policy makers. In the tourism research area, many empirical results indicated that tourism development and economic growth exists causal relationship in several nations [1]-[11]. For example, [1] showed that there is a long run equilibrium relationship between tourism development and economic growth. They conducted a standard Granger causality test and showed that there is one-way causal relationship between tourism development and economic growth with Spanish data. Their empirical results support the tourism-led growth hypothesis. [3] employed the leveraged bootstrap causality to examine the impact of tourism on the Turkey economy and also support the tourism-led growth hypothesis. However, using data of South Korea and developing countries, [7] and [8] found that by using the co-integration analysis, there is no long-run relationship between tourism receipts and economic growth in South Korea and developing countries. On the other hand, [2] and [9] found a bi-directional relationship between tourism expansion and economic development.

Furthermore, using the panel data for 55 counties, [10] indicated that there are causal relationships between tourism development and economic growth for Organization for Economic Co-operation and Development (OECD) countries and for non-OECD countries including those in Asia, Latin America and Sub-Sahara African countries for the period from 1990 to 2002. [11] also used the threshold regression for 88 countries to examine the relationship between tourism development and economic growth, and found that tourism development does not necessarily bring about economic growth under certain conditions.

To summarize, we found that increase in tourism development may or may not promote the economic growth. Moreover, according to [12], tourism may have many beneficial effects, but it also generates some social and environmental costs, and opportunity cost that are normally overlooked. Therefore, whether or not the development of tourism strengthens the economy will depend on whether the benefits outweigh the negative impacts on tourism. In other words, whether the development of tourism has a positive impact on economic growth is still debatable. On the other hand, the above empirical studies overlooked one of the key factors, export growth, which affects economic growth. According to [13]-[15] empirical studies, they found that there existed the causal relationship between export growth and economic growth. [16] examine the long-run relationship among tourism, trade, and growth in Cyprus and showed that tourism, trade and real income growth are co-integrated; 
therefore, there is a long-run equilibrium relationship among these three variables.

The purpose of this paper is to investigate either if there is the direct relationship from tourism development to economic growth in Taiwan, or there is the indirect relationship from tourism development to economic growth through export growth in Taiwan, or if there exist both an indirect and indirect relationship. Moreover, in this study we employed an innovative methodology proposed by [17], which is totally different from the past research studies and called a quantile mediation analysis. This innovative method combines a quantile regression, which is more robust [18] and [19] because it estimates the median and the full range of other conditions, rather than ordinary least squares (OLS) regression to estimate mean, proposed by [20] and mediation analysis proposed by [21] to investigate the dynamic short-run causal impact of tourism development on economic growth across different conditional economic growth from 1990 to 2018 in Taiwan. The remainder of this paper is simply organized as follows. Section 2 describes research methodology. Section 3 explains data collection and results from empirical analysis. In section 4 , we present the concluding discussion and further comments.

\section{Research Methodology}

\subsection{Quantile Regression: Various Studies}

A quantile regression is a statistical technique intended to estimate, and conduct inference about conditional quantile function. [20] proposed the quantile regression approach as an alternative to least squares regression in a wide range of applications. This approach takes into consideration the skewness of the distribution and gives a more complete picture of the way performance is affected by the various independent variables. This technique was further developed by [18] and [19]. Recently, the quantile regression has been receiving much attention for theoretical as well as empirical work, on a wide range of issues in economics. For example, [22] examined the evolution of the returns to education in Portugal during the 1980s and early 1990s by using OLS and quantile regression estimators. [23] used quantile regression methods to consider the issue of income convergence and the effects of policy variables on the conditional distribution of GDP growth rates. [24] used it for estimating gender wage differentials in Philippines. [25] used it for estimating economic volatility and returns to education in Venezuela. [26] used it for an analysis of the wage premium associated with technological change. [27] employed Quantile regression for an analysis the important aspect of parametric differences across high-growth and low-growth countries.

\subsection{An Introduction of a Quantile Regression}

A quantile regression which was introduced by Koenker and Bassett [18] offered a mechanism for estimating models for the conditional median function, and the full range of other conditional quantile functions. Whereas the method of ordinary least-squares regression results in estimates that approximate the conditional mean of the response variable, given certain values of the predictor variables, quantile regression results in estimates approximating either the median or other quantiles of the response variable. By supplementing the estimation of conditional mean functions with techniques for estimating an entire family of conditional quantile functions, quantile regression is capable of providing a more complete statistical analysis of the stochastic relationships among random variables.

According to [19], a quantile regression is used when an estimate of the various quantile of a population is desired. One advantage of using quantile regression to estimate the median and the full range of other conditions, rather than ordinary least squares regression to estimate mean, is that a quantile regression will be more robust in response to large outliers. Like the least absolute deviations, the quantile regression objective function is a weighted sum of absolute deviations, which gives a robust measure of location, so that the estimated coefficient vector is not sensitive to outlier observations on the dependent variable. In addition, it also provides a more efficient approach than the least square method when the error term is non-normal.

A quantile regression can be seen as a natural analogue in regression analysis to the practice of using different measures of central tendency and statistical dispersion to obtain a more comprehensive and robust analysis. Another advantage to quantile regression is the fact that any quantile can be estimated.

According to [20] method, we let $\left\{y_{t}, t=1,2 \ldots, T\right\}$ be a random sample on the regression process $y_{t}=u_{t}+x_{t} \beta$, having conditional distribution function $F_{Y / X}(y)=$ $F\left(Y_{t} \leq y\right)=F\left(y_{t}-x_{t} \beta\right)$, where $\left\{x_{t}, t=1,2 \ldots, T\right\}$ denote a sequence of (row) k-vectors of a known design matrix. The $\theta^{\text {th }}$ regression quantile, $Q_{Y / X}(\theta)$, is between 0 and 1 , given any $\theta$ to obtain the estimate $\beta$ in order to get the weighted sum of absolute value of the error term is the minimum value for equation (1)

$$
\begin{gathered}
\min _{\beta}\left[\theta \sum\left|y_{t}-x_{t} \beta\right|+(1-\theta) \sum\left|y_{t}-x_{t} \beta\right|\right] \\
\left\{t: Y_{t} \geq X_{t} \beta\right\} \quad\left\{t: Y_{t}<X_{t} \beta\right\}
\end{gathered}
$$

Equation (1) is the weighted sum of absolute values consists of two parts, if the observation value is greater than or equal to the estimate, the weight is $\theta$, or if the observation value is less than the estimate, the weight is $1-\theta$. The resulting solution to equation (1) is denoted as $\beta_{\theta}$, from which we obtain the $\theta^{\text {th }}$ conditional quantile $Q_{Y / X}(\theta)=x \beta_{\theta}$. In this paper, the dependent variable, $y_{t}$, is the yearly real gross domestic product (GDP) and the independent variables, $x_{t}$, include the yearly international tourism real receipts (TOUR) and the yearly total amounts of the exports (EXPO) which are 
considered to the important variable which affects the economic growth in many empirical studies [13]-[15].

\subsection{Meditation Analysis on Economic Growth}

We can use mediation analysis to investigate the causality from tourism development to economic growth through export growth and the direct relation between tourism development and economic growth in equations 2 to 4 . The most common approach to examine mediation effect is the causal steps proposed by [21]. According to [21], they establish the following regression equations relating the independent variable, mediator variable, and dependent variable:

$$
\begin{aligned}
& \text { GROW }=b_{0}+b_{1} \text { TOUR }+e_{1} \\
& \text { EXPO }=c_{0}+c_{1} \text { TOUR }+e_{2} \\
& \text { GROW }=d_{0}+d_{1} \text { TOUR }+d_{2} \text { EXPO }+e_{3}
\end{aligned}
$$

Here, the tourism development (TOUR) is measured as the yearly international tourism real receipts and EXPO is the yearly total amounts of the exports. Economic growth (GROW) is measured as the real Gross Domestic Product. Technically, $e_{i}, i=1,2,3$ is the stochastic error term. Meditation analysis on export growth processes are as following:

Step 1: The independent variable TOUR needs to relate to the dependent variable GROW, such that $b_{1}$ in Equation 2 is significant. This condition is used to establish that there is a direct relationship between TOUR and GROW to be mediated.

Step 2: The independent variable TOUR needs to relate to the mediator variable EXPO, such that $c_{1}$ in Equation 3 is significant. This condition establishes the first stage of the mediated effect.

Step 3: The mediator variable EXPO should relate to the dependent variable GROW, such that $d_{2}$ in Equation 4 is significant. This condition establishes the second stage of the mediated effect.

Step 4: The independent variable TOUR should no longer relate to the dependent variable GROW after the mediator variable EXPO is controlled, such that $d_{1}$ in Equation 4 is not significant. This condition shows that the relationship between TOUR and GROW examined under the first condition disappears when the mediated effect transmitted through EXPO is considered.

Satisfying all four steps provides evidence for complete mediation, whereas satisfying the first three steps indicates partial mediation if $\mathrm{d}_{1}$ in Equation 4 is still significant and is smaller than $b_{1}$ in Equation 2.

\subsection{A Quantile Meditation Analysis}

An innovative method, proposed by [17], combines a meditation analysis and quantile regression which substitute equation 1 into equations 2 to 4 , can be described to equations 5 to 7 . This analysis provides a useful supplement to the standard constant-parameter regression estimate (only one b or c or d) for studying all possible parameters (for all quantiles) vary across high dependent variable and low dependent variable. This novel method also leads to a more dynamic and complete understanding of what might really lie behind the stories of great effect or non-effect for tourism development on economic growth. The quantile regression minimizes a weighted sum of the positive and negative error terms in equations 5 to 7 .

$$
\begin{aligned}
& \min _{b} \theta \sum \mid \mathrm{GROW}_{\mathrm{t}}-b_{0}-b_{1} \text { TOUR }_{\mathrm{t}} \mid+ \\
& (1-\theta) \sum \mid \mathrm{GROW}_{\mathrm{t}}-b_{0}-b_{1} \text { TOUR }_{\mathrm{t}} \mid \\
& \min _{c} \theta \sum \mid \mathrm{EXPO}_{\mathrm{t}}-c_{0}-c_{1} \text { TOUR }_{\mathrm{t}} \mid+ \\
& (1-\theta) \sum \mid \mathrm{EXPO}_{\mathrm{t}}-c_{0}-c_{1} \text { TOUR }_{\mathrm{t}} \mid \\
& \min _{d} \theta \sum \mid \mathrm{GROW}_{\mathrm{t}}-d_{0}-d_{1} \text { TOUR }_{\mathrm{t}}-d_{2} \text { EXPO }_{\mathrm{t}} \mid+ \\
& (1-\theta) \sum \text { GROW }_{\mathrm{t}}-d_{0}-d_{1} \text { TOUR }_{\mathrm{t}}-d_{2} \text { EXPO }_{\mathrm{t}} \mid
\end{aligned}
$$

Then we use the above four steps in section 2.3 meditation analysis on economic growth to examine if there is the direct relationship from tourism development to economic growth in Taiwan, or there is the indirect relationship from tourism development to economic growth through export growth in Taiwan, or if there exist both an indirect and indirect relationship in equation (5) to (7).

\section{Empirical Results}

This study uses annual Taiwan data that covers the period 1990-2018. The data of the real gross domestic product, the real receipts of international tourism and the total amount of exports were taken from the Taiwan Economic Journal. All variables are in logarithmic form (standardized values).

Before estimating equations 2 to 4 or 5 to 7 , we employed the Augmented Dickey-Fuller (ADF) unit root test to examine the null hypothesis that a unit root is present in a time series and to determine the order of integration of these three variables. Table 1 display the unit root test results in levels and first differences with trend and intercept. The results show that we cannot reject the null hypothesis of the unit root for three variables in levels because $\mathrm{p}$ value is greater than 0.05 . However, we reject the null hypothesis of a unit root at the $1 \%$ significant level or better for the first- value difference of these three variables since $p$ value is smaller than 0.01. Based on the results from the ADF test, these three data series integrated of order one.

Table 1 Results from the Augmented Dickey-Fuller Unit Root Test

Variable Level p-value 1st difference p-value

\begin{tabular}{lllll}
\hline TOUR & -2.051 & 0.549 & -4.897 & $0.003^{*}$ \\
EXPO & -2.642 & 0.266 & -5.929 & $0.000^{*}$ \\
GROW & -1.928 & 0.613 & -5.397 & $0.001^{*}$
\end{tabular}

* Denotes significance at the $1 \%$ level. 
Regarding the causal relationship between tourism development and economic growth, and tourism development and export growth in equations 2 and 3 or 5 and 6 , we demonstrate the causality test results in Table 2 . The notation of TOUR $\neq>$ GROW means that the variable TOUR does not affect the variable GROW, Similar to TOUR $\neq>$ EXPO and $\mathrm{EXPO} \neq>$ GROW.

We find out some remarkable results as follows in table 2 . First, there is the causal relationship from tourism development to economic growth by using traditional ordinary least square method (OLS). Second, by using a quantile mediation approach, there also exists causality running from tourism development to economic growth at any distributions of economic growth. Lastly, there exists causality running from tourism development to export growth by using traditional OLS method and at any distributions of export growth. This result establishes the first stage of the mediated effect. It asserts that we consider the mediated effect at any distributions of export growth. In other words, no matter what if the export growth is high or low, tourism development affects export growth.

Table 2 Results from TOUR to GROW and from TOUR to EXPO at Different Quantiles

\begin{tabular}{|c|c|c|c|c|}
\hline \multirow[t]{2}{*}{ Quantile } & \multicolumn{2}{|c|}{ TOUR $\neq>$ GROW } & \multicolumn{2}{|c|}{ TOUR $\neq>$ EXPO } \\
\hline & b1 & p-value & $\mathrm{c} 1$ & $\mathrm{p}$-value \\
\hline 0.20 & $0.990 *$ & 0.000 & $0.949 *$ & 0.000 \\
\hline 0.40 & $1.006^{*}$ & 0.000 & $0.985 *$ & 0.000 \\
\hline 0.50 & $0.947 *$ & 0.000 & $0.989 *$ & 0.000 \\
\hline 0.60 & $0.911 *$ & 0.000 & $0.977^{*}$ & 0.000 \\
\hline 0.80 & $0.695^{*}$ & 0.001 & $0.692 *$ & 0.001 \\
\hline OLS & $0.940 *$ & 0.000 & $0.933^{*}$ & 0.000 \\
\hline
\end{tabular}

*Denotes significance at the $5 \%$.

The table 3 shows that $\mathrm{d} 2$ is significant both by using traditional OLS in equation 4 and a quantile mediation approach at any distribution of economic growth in Equation 7, that is, the mediator variable EXPO relates to the dependent variable GROW. This result establishes the second stage of the mediated effect. That is, the export growth is a mediator variable.

Furthermore, through the OLS method, the variable TOUR should no longer relate to the dependent variable GROW after the mediator variable EXPO is controlled, such that $\mathrm{d} 1$ is not significant in Equation 4. This condition shows that the relationship between TOUR and GROW examined under the first condition disappears when the mediated effect transmitted through EXPO is considered. This result evidences the complete mediation because of satisfying all four steps in equations 2 to 4 .

Third, through a quantile mediation analysis, the variable TOUR also no longer relates to the dependent variable GROW after the mediator variable EXPO is controlled at below 0.6 distributions of economic growth in table 3 since $\mathrm{d} 1$ is not significant in Equation 7. This condition shows that the relationship between TOUR and GROW examined under the first condition disappears when the mediated effect transmitted through EXPO is considered. This result evidences the complete mediation because of satisfying all four steps in equations 5 to 7 . However, at 0.8 distribution of economic growth, the result only satisfies the first three steps, which indicates partial mediation since $d_{1}$ in Equation 7 is still significant and is smaller than $b_{1}$ in Equation 5.

The results of the effects of tourism development on economic growth are different from the previous results. Appling traditional ordinal least square method, we find tourism development affects economic growth through the full mediation effect of export growth for the period of 1990-2018 and there is no direct relation between tourism development and economic growth, which is totally different from the previous empirical findings in [1] to [11]. Moreover, by using a quantile mediation analysis, we find more dynamic results. Tourism development affects economic growth through the full mediation effect of export growth at below 0.6 distributions of economic growth. To put it another way, when Taiwan's economic growth is lower, tourism development affects economic growth only through export growth. Lastly, at above 0.6 distributions of economic growth, there exist direct and partially mediation effects from tourism development to economic growth in Taiwan. In other words, when Taiwan's economic growth is higher, not only tourism development affects economic growth, but also affects economic growth through export growth.

Table 3 Results from TOUR and EXPO to GROW at Different Quantiles

\begin{tabular}{lllll}
\hline Quantile & \multicolumn{2}{c}{ TOUR $\neq>$ GROW } & \multicolumn{2}{c}{ EXPO $\neq>$ GROW } \\
& $\mathrm{d} 1$ & p-value & $\mathrm{d} 2$ & p-value \\
& & & & \\
\hline 0.20 & 0.099 & 0.523 & $0.895^{*}$ & 0.000 \\
0.40 & 0.095 & 0.550 & $0.882^{*}$ & 0.000 \\
0.50 & 0.215 & 0.128 & $0.825^{*}$ & 0.000 \\
0.60 & 0.190 & 0.187 & $0.871^{*}$ & 0.000 \\
0.80 & $0.303^{*}$ & 0.036 & $0.626^{*}$ & 0.006 \\
OLS & 0.155 & 0.086 & $0.840^{*}$ & 0.000
\end{tabular}

*Denotes significance at the $5 \%$.

\section{Conclusions}

Several empirical literatures have examined the causal relationship from tourism development to economic growth. Most research results found a directly positive effect of tourism development on economic growth by using the ordinary least square method. However, the empirical studies overlooked export growth, which affects economic growth. In this paper we not only investigate if there is the direct relationship from tourism development to economic growth in Taiwan, but also if there is the indirect relationship from tourism development to economic growth through export growth in Taiwan. 
Moreover, in this study we employed an innovative methodology which combines a quantile regression, which has allowed to obtain the full characterization of the conditional distribution of the dependent variable economic growth in our study rather than its conditional mean only, and mediation analysis. That is, we provide a comprehensive picture of tourism development to economic growth in Taiwan over the period of 1990 to 2018 whether Taiwan's economic growth is high or low. The result of the traditional ordinary least square approach shows that Taiwan's tourism development affects economic growth through the full mediation effect of export growth for the period of 1990-2018 and there is no direct relation between tourism development and economic growth.

Lastly, the results of this innovative analysis demonstrate that Taiwan's tourism development also affects economic growth through the full mediation effect of export growth at below 0.6 distributions of economic growth, but at above 0.6 distributions of economic growth, there exist direct and indirect effect from tourism development to economic growth. From the results, we suggest that Taiwan's government should focus on the export growth if she wants to promote Taiwan's economic growth when the economy is in a recession, not focus on tourism development.

\section{REFERENCES}

[1] M. Balaguer and M. Cantavella-Jorda, "Tourism as a long-run economic growth factor: The Spanish case", Applied Economics, Vol. 34, pp. 877$884,2002$.

[2] N. Dritsakis, "Tourism as a long-run economic growth factor: An empirical investigation for Greece using a causality analysis", Tourism Economics, Vol. 10, pp. 305-316, 2004.

[3] L. Gunduz and A. Abdulnasser, "Is the tourism-led growth hypothesis valid for Turkey?", Applied Economics, Vol. 12, pp. 499-504, 2005.

[4] Kreishan, F. M. M., "Tourism and Economic Growth: The Case of Jordan", European Journal of Social Sciences, Vol. 15, No.2, pp. 229-234, 2010.

[5] N. Dritsakis, "Tourism Development and Economic Growth in Seven Mediterranean Countries: A Panel Data Approach", Tourism Economics, Vol. 18, No. 4, pp. 801-816, 2012.

[6] A. Khan, S. Bibi, A. Lorenzo, J. Lyu and Z. U. Babar, "Tourism and Development in Developing Economies: A Policy Implication Perspective", Sustainability, Vol. 12, pp. 1-19, 2020.

[7] C. O. Oh, "The contribution of tourism development to economic growth in the Korean economy”, Tourism Management, Vol. 26, pp. 39-44, 2005.

[8] E. M. Ekanayake and A. E. Long, "Tourism Development and Economic Growth in Developing Countries", The International Journal of Business and Finance Research, Vol. 6, No. 1, pp. 51-63, 2012.

[9] H. J. Kim, M. H. Chen and S. C. Jang, "Tourism expansion and economic development: The case of Taiwan", Tourism Management, Vol. 27, pp. 925-933, 2006.

[10] C. C. Lee and C. P. Chang, "Tourism development and economic growth: A closer look at panels", Tourism Management, Vol. 29, pp. 180-192, 2008.

[11] W. C. Po and B. N. Huang, "Tourism development and economic growth- a nonlinear approach". Physica A, Vol. 387, pp. 5535-5542, 2008.

[12] T. Palmer and A. Riera, "Tourism and environmental taxes: With special reference to the Balearic ecotax", Tourism Management, Vol. 24, pp. 665-674, 2003.

[13] B. Balassa, "Exports and economic growth: further evidence, Journal of Development Economics, Vol. 5, pp. 181-189, 1978.

[14] D. Marin, "Is the export-led growth hypothesis valid for industrialized countries?", Review of Economics and Statistics, Vol. 74, pp. 678-688, 1992.

[15] J. A. Frankel and D. Romer, "Does trade cause growth ?", American Economic Review, Vol. 89, pp. 379-399, 1999.
[16] S. Katircioglu, "Tourism, trade and growth: the case of Cyprus", Applied Economcs, Vol. 41, pp. 2741-2750, 2009.

[17] T. K. Hsu, "Exploring the Impact of Openness on Inflation in Taiwan: Mediation Analysis With A Quantile Approach", WSEAS Transactions on Business and Economics, Vol. 17, pp. 133-139, 2020.

[18] R. Koenker and K. Hallock, "Quantile regression", The Journal of Economic Perspectives, Vol. 15, pp. 143-156, 2001.

[19] R. Koenker, Quantile Regression, Econometric Society Monograph Series, Cambridge University Press, 2005.

[20] R. Koenker and G. Bassett, "Regression Quantile", Econometrica, Vol. 46, pp. 33-49, 1978.

[21] R. M. Baron and D. A. Kenny., "The Moderator-Mediator Variable Distinction in Social Psychological Research: Conceptual, Strategic, and Statistical Considerations", Journal of Personality and Social Psychology, Vol. 51, No. 6, pp. 1173-1182, 1986.

[22] J. Hartog, P. T. Pereira and A. C. Vieira, "Changing returns to education In Portugal during the 1980s and early 1990s: OLS and quantile regression estimators", Applied Economics, Vol. 33, pp. 1021-1037, 2001.

[23] M. Mello and P. Roberto, "Growth equation: A quantile regression exploration", Quarterly Review of Economics and Finance, Vol. 43, pp. 643-667, 2003.

[24] C. Sakellariou, "The use of quantile regressions in estimating gender wage differentials: a case study of the Philippines", Applied Economics, Vol. 36, pp. 1001-1007, 2004.

[25] H. A. Patrinos and C. Sakellariou, "Economic volatility and returns to education in Venezuela: 1992-2002", Applied Economics, Vol. 38, pp. 1991-2005, 2006.

[26] K. S. Choi and J. Jeong, "Does unmeasured ability explain the wage premium associated with technological change? Quantile regression analysis", Applied Economics, Vol. 39, pp. 1163-1171, 2007.

[27] R. Ram, "Parametric variability in cross-country growth regressions: An application of quantile-regression methodology", Economics Letters, Vol. 99, pp. 387-389, 2008

\section{Creative Commons Attribution License 4.0 (Attribution 4.0 International, CC BY 4.0)}

This article is published under the terms of the Creative Commons Attribution License 4.0 https://creativecommons.org/licenses/by/4.0/deed.en US 